Provided for non-commercial research and education use. Not for reproduction, distribution or commercial use.

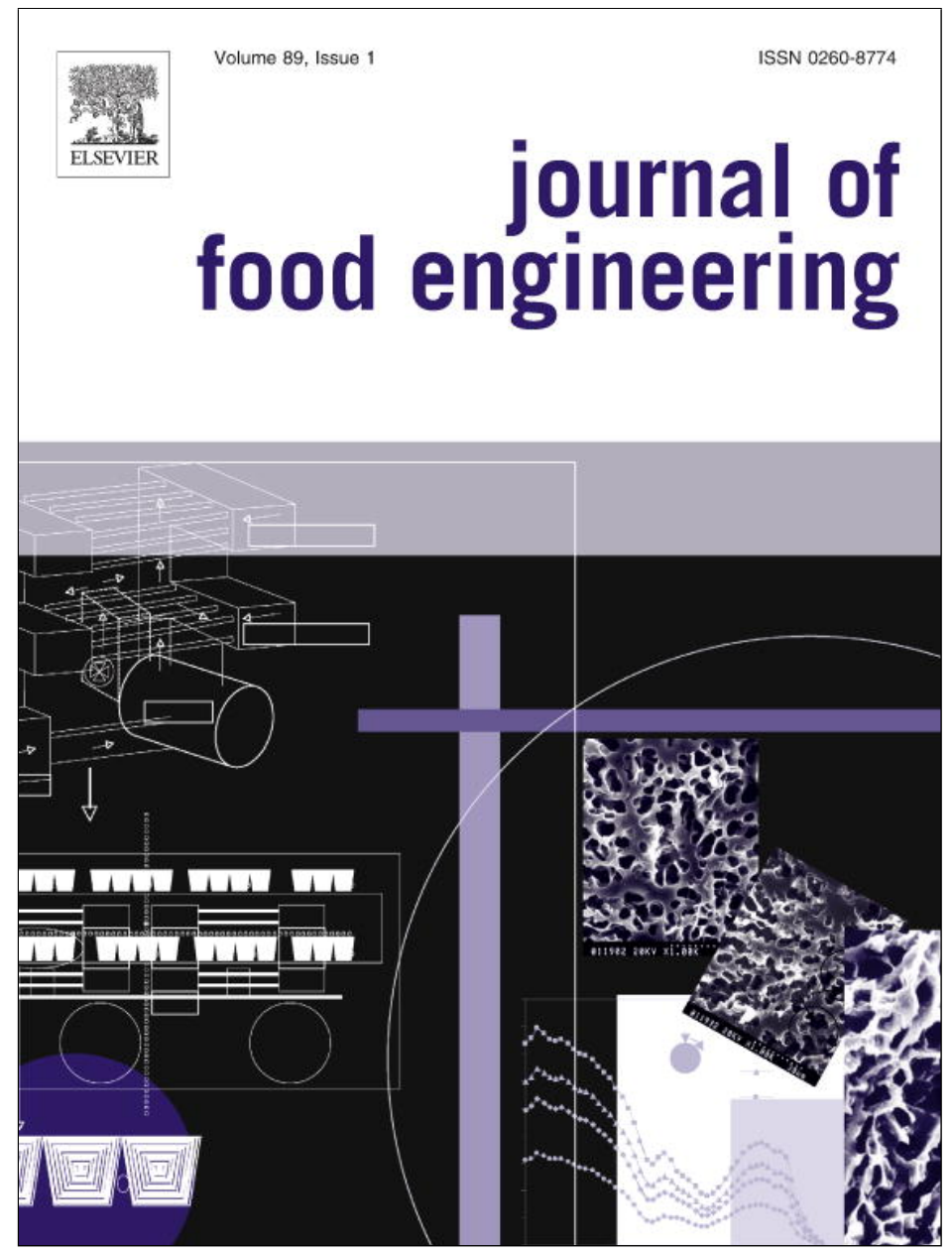

This article appeared in a journal published by Elsevier. The attached copy is furnished to the author for internal non-commercial research and education use, including for instruction at the authors institution and sharing with colleagues.

Other uses, including reproduction and distribution, or selling or licensing copies, or posting to personal, institutional or third party websites are prohibited.

In most cases authors are permitted to post their version of the article (e.g. in Word or Tex form) to their personal website or institutional repository. Authors requiring further information regarding Elsevier's archiving and manuscript policies are encouraged to visit:

http://www.elsevier.com/copyright 


\title{
Combined discrete element and CFD modelling of airflow through random stacking of horticultural products in vented boxes
}

\author{
M.A. Delele*, E. Tijskens, Y.T. Atalay, Q.T. Ho, H. Ramon, B.M. Nicolaï, P. Verboven \\ BIOSYST-MeBioS, Katholieke Universiteit Leuven, Willem de Croylaan 42, 3001 Leuven, Belgium
}

\section{A R T I C L E I N F O}

\section{Article history:}

Received 28 November 2007

Received in revised form 11 March 2008

Accepted 31 March 2008

Available online 7 April 2008

\section{Keywords:}

Discrete element method

Computational fluid dynamics

Cooling

Airflow

Porous media

Numerical simulation

\begin{abstract}
A B S T R A C T
A direct model, using the explicit geometry of stacked products in boxes, was developed and used to study the local and average airflow through stacks of horticultural products. The discrete element method was employed to generate a random stacking of spherical products in the box. A computational fluid dynamics model was then applied to study explicitly the airflow through the air gaps in the box and in the voids between the stacks of different random fillings. The flow resistance was affected by the confinement ratio, product size, porosity, box vent hole ratio, and much less by the random filling. The predicted pressure drop over stacks agreed with experimental correlations for porous media. Air velocity profiles inside the boxes compared well to measurements. The methodology was used to obtain more accurate pressure drop correlation for stacks of vented boxes that can now be used in large scale simulations of cool rooms.
\end{abstract}

(c) 2008 Elsevier Ltd. All rights reserved.

\section{Introduction}

For cooling horticultural products, cold air is usually forced through the container (box) and the stored product. However, the flow resistance induced by the box and the product is affecting the cooling efficiency. Effective box venting could enhance the cooling efficiency, but the design of the venting should take into account the strength of the box. Vingeault and Goyette (2002) studied the pressure loss through vented plastic boxes and a vent hole ratio of $25-27 \%$ was recommended. The non-homogeneous flow of the cooling air inside the stack could also cause uneven cooling and product quality (Alvarez and Flick, 1999a,b, 2007; Verboven et al., 2004, 2006).

Several previous studies conducted experiments and developed correlations that could estimate pressure loss through the box with horticultural product (Chau et al., 1985; Smale, 2004; van der Sman, 2002; Verboven et al., 2004; Vingeault and Goyette, 2002; Vingeault et al., 2004). All the correlations were described either in the form of Darcy-Forchheimer equation (Forchheimer, 1901)

$\nabla p=-\frac{\mu}{K} \boldsymbol{u}-\beta \rho|\boldsymbol{u}| \boldsymbol{u}$

or the power-law relationship of Ramsin equation (Chau et al., 1985)

$\nabla p=-a \boldsymbol{u}^{b}$

\footnotetext{
* Corresponding author. Tel.: +32 16322376; fax: +32 16322955.

E-mail address: mulugetaadmasu.delele@biw.kuleuven.be (M.A. Delele).
}

The parameters $K$ and $\beta$ in Eq. (1) depend on stacked product diameter, porosity, stacking pattern, fluid property, product shape, roughness, confinement ratio $\left(D_{\mathrm{h}} / d_{\mathrm{p}}\right)$ and box vent hole ratio $\left(O=A_{\text {hole }} / A_{\text {box }}\right)$ (Chau et al., 1985; Eisfeld and Schnitzlein, 2001; van der Sman, 2002; Verboven et al., 2004, 2006). For smooth spherical objects, the most popular expressions for parameters $K$ and $\beta$ are given in Table 1 . The Ergun (1952) correlation does not consider any effect of the confining and vented box walls, and mainly applicable to bulk stacks of infinite size. Confining the bulk in a container causes an additional resistance due to wall friction; moreover, it creates a region with increased porosity near the wall of the container. For $D_{\mathrm{h}} / d_{\mathrm{p}}<10$ and flow with low particle Reynolds number $\left(R e_{\mathrm{d}}=\frac{\rho|\mathbf{u}| d_{\mathrm{p}}}{\mu}<10\right)$, a decrease in $D_{\mathrm{h}} / d_{\mathrm{p}}$ increases the pressure drop; where as, for a high Reynolds number flow $\left(R e_{\mathrm{d}}>300\right)$ a decrease in $D_{\mathrm{h}} / d_{\mathrm{p}}$ decreases the pressure drop (Di Felice and Gibilaro, 2004; Eisfeld and Schnitzlein, 2001; Verboven et al., 2004, 2006). Reichelt (1972) developed a correlation that took into account the contribution of confining walls to hydraulic diameter through the analytical constant $A_{\mathrm{w}}$ and the porosity effect of the confining wall at high Reynolds number through an empirical function $B_{\mathrm{w}}$. See the detail equations in Table 1. For unconfined bulk (high confinement ratio), $A_{\mathrm{w}}$ equals 1 and $B_{\mathrm{w}}$ equals $k_{2}$. According to the model developed by van der Sman (2002), for vented box containers the total pressure drop is proportional to $O^{-1.5}$. However, the pressure drop can also be affected by vent hole design and the depth of the bulk, the general use of such simple formula as developed by van der Sman (2002) may be questionable (Smale, 2004; Verboven et al., 2006). In Eq. 


\begin{tabular}{|c|c|c|c|}
\hline \multicolumn{4}{|c|}{ Nomenclature } \\
\hline$\alpha$ & resistance coefficient, $\mathrm{kg} \mathrm{s}^{b-2} / \mathrm{m}^{(b+2)}$ & $p$ & pressure, $\mathrm{Pa}$ \\
\hline$A_{\text {box }}$ & box face area, $\mathrm{m}^{2}$ & $p_{\mathrm{c}}$ & pressure drop calculated from fitted equation, $\mathrm{Pa}$ \\
\hline$A_{\text {hole }}$ & vent hole area, $\mathrm{m}^{2}$ & $p_{\mathrm{s}}$ & pressure drop from simulation, $\mathrm{Pa}$ \\
\hline$A_{\mathrm{w}}$ & confinement parameter & $r^{2}$ & coefficient of determination \\
\hline$b$ & resistance exponent & $R e_{\mathrm{d}}$ & particle Reynolds number \\
\hline$B_{\mathrm{w}}$ & confinement parameter & $t$ & time, $s$ \\
\hline$C$ & resistance coefficient, $1 / \mathrm{m}$ & $\boldsymbol{u}$ & velocity vector, $\mathrm{m} / \mathrm{s}$ \\
\hline$d$ & constant & $u_{i}, u_{j}$ & mean velocity components in $X, Y$, and $Z$ directions, \\
\hline$d_{\mathrm{p}}$ & effective product diameter, $\mathrm{m}$ & & $\mathrm{m} / \mathrm{s}$ \\
\hline$D_{\mathrm{h}}$ & package hydraulic diameter, $\mathrm{m}$ & $u_{i}^{\prime}, u_{j}^{\prime}$ & fluctuating velocity components, $\mathrm{m} / \mathrm{s}$ \\
\hline E & relative difference, \% & $x_{i}, x_{j}$ & Cartesian coordinates, $\mathrm{m}$ \\
\hline$k$ & turbulent kinetic energy, $\mathrm{m}^{2} / \mathrm{s}^{2}$ & $\beta$ & Forchheimer drag coefficient, $1 / \mathrm{m}$ \\
\hline K & Darcy permeability, $\mathrm{m}^{2}$ & $\beta_{\mathrm{c}}$ & resistance coefficient \\
\hline$k_{1}$ & coefficient of wall effect correction term & $\delta_{i j}$ & kronecker delta \\
\hline$k_{2}$ & coefficient of wall effect correction term & $\varepsilon$ & porosity \\
\hline$K_{1}$ & coefficient of pressure drop correction term & $\mu$ & dynamic viscosity, $\mathrm{kg} / \mathrm{ms}$ \\
\hline$K_{\mathrm{c}}$ & resistance coefficient, m & $\mu_{\mathrm{t}}$ & turbulent viscosity, $\mathrm{kg} / \mathrm{ms}$ \\
\hline l & bulk length, m & $\rho$ & density, $\mathrm{kg} / \mathrm{m}^{3}$ \\
\hline$m$ & resistance coefficient, $\mathrm{kg} \mathrm{s}^{b-2} / \mathrm{m}^{(b+2)}$ & & \\
\hline$m_{\mathrm{r}}$ & resistance coefficient, $\mathrm{kg} \mathrm{s}^{b-2} / \mathrm{m}^{(b+1)}$ & \multicolumn{2}{|c|}{ Subscripts } \\
\hline$N$ & number of data & $i, j$ & Cartesian coordinate index \\
\hline 0 & vent hole ratio, \% & & \\
\hline
\end{tabular}

Table 1

The most popular expressions for parameters $\frac{1}{K}$ and $\beta$

\begin{tabular}{llll}
\hline Parameter & Equation & & \\
\cline { 2 - 4 } & Infinite packaging & Finite packaging & Vented box \\
\hline$\frac{1}{K}, \mathrm{~m}^{2}$ & $\frac{1}{K}=\frac{150(1-\varepsilon)^{2}}{d_{\mathrm{p}}^{2} \varepsilon^{3}}$ & $\begin{array}{l}\frac{1}{K}=\frac{K_{1} A_{\mathrm{w}}^{2}(1-\varepsilon)^{2}}{d_{\mathrm{p}}^{2} \varepsilon^{3}} \\
A_{\mathrm{w}}=1+\frac{2}{3\left(D_{\mathrm{h}} / d_{\mathrm{p}}\right)(1-\varepsilon)}\end{array}$ & - \\
$\beta, m^{-1}$ & $\beta=\frac{1.75(1-\varepsilon)}{d_{\mathrm{p}} \varepsilon^{3}}$ & $\beta=\frac{A_{\mathrm{w}}(1-\varepsilon)}{B_{\mathrm{w}} d_{\mathrm{p}} \varepsilon^{3}}$ & $\beta=C O^{-1.5}$ \\
Source & Ergun (1952) & Reichelt $(1972)$ & van der Sman (2002) \\
\hline
\end{tabular}

(2), the parameters $a$ and $b$ depend on stacking pattern, diameter and porosity (Chau et al., 1985). Based on experimental results, Vingeault et al. (2004) estimated the values of $a$ and $b$ for products with different shape and characteristics. The effect of box vent hole ratio on these parameters were also studied (Vingeault and Goyette, 2002; Vingeault et al., 2004; Smale, 2004). Smale (2004) described the constant $a$ as a function of vent hole ratio $\left(a=m O^{d}\right)$.

The use of these correlations for studying the local flow behaviour, the aerodynamic box design and stacking pattern is very limited. These correlations are mainly useful for process calculations. In forced-air cooling processes, to study the preferential airflow pathways through vented boxes with horticultural products, the use of a direct CFD approach has been recommended (Verboven et al., 2006). Several previous studies proved the applicability of CFD and Lattice-Boltzmann simulations for studying flows through explicitly modelled packed beds of spheres (Beetstra et al., 2006, 2007; Dixon and Nijemeisland, 2001; Dixon et al., 2005; Freund et al., 2003; Hill et al., 2001; Nijemeisland and Dixon, 2004); however, none of these studies used the discrete element (DE) model for generating the packed bed. In studying the flow in fluidized beds, the discrete particle modelling method has been used more extensively (Deen et al., 2006, 2007; Li and Kuipers, 2007; van der Hoef et al., 2004). This study combined the concepts from the two fields: the discrete particle modelling method was used to create random stacks in a box and direct CFD modelling was used to study the flow through these stacked products.

The objective of this work was to develop a validated numerical modelling methodology that takes into account product geometri- cal properties, box design and randomness of product stacking, explicitly in the model formulation for predicting the air flow through stacks of boxes with horticultural products.

\section{Materials and methods}

\subsection{The DE method and product stacking}

The DE method was employed to generate a random stacking of spheres in the box. The DE method is a numerical technique for solving Newton's equations of motion of an assembly of interacting particles. Forces accounted for are the gravity and contact forces due to collision with other spheres or walls. Contact forces are described by a contact force model (Tijskens et al., 2003).

For studying the flow through confined and unconfined stacks, non-uniform sized spheres with a diameter range from 65 to $75 \mathrm{~mm}$ were randomly generated. Whereas to investigate and validate the air flow through loaded vented boxes, uniform sized spheres of $75 \mathrm{~mm}$ diameter were used. The stacking was made for the following three cases:

- Case 1, six layers of 300 spheres with a diameter of 65-75 mm randomly stacked in a box of $0.38 \mathrm{~m}$ long, $0.55 \mathrm{~m}$ wide and $0.42 \mathrm{~m}$ high. This stack represents a relatively large confined bulk with a confinement ratio of 6.8. From the centre of this stack a sub-domain was also cut to study the flow though unconfined stack.

- Case 2, similar to case 1 but two layers of 70 spheres and the width and height of the box changed to $0.45 \mathrm{~m}$ and $0.13 \mathrm{~m}$, respectively. This stack was used to study the flow through a relatively small confined bulk with a confinement ratio of 2.8 .

- Case 3, two layers of 32 spheres with a diameter of $75 \mathrm{~mm}$ each randomly stacked in a $0.38 \mathrm{~m}$ length, $0.14 \mathrm{~m}$ height and $0.28 \mathrm{~m}$ width box (Fig. 1). The confinement ratio of this stack was 2.4. The bulk from Case 3 was also used to study vented EPS (Euro Pool System, Leidschendam, The Netherlands) boxes of dimensions $30 \times 40 \times 16 \mathrm{~cm}$ (Fig. 2). The vent hole ratios of the side, front, and bottom box surfaces were $11.03 \%, 14.36 \%$ and $19.10 \%$, respectively. For two boxes that were place side by side 

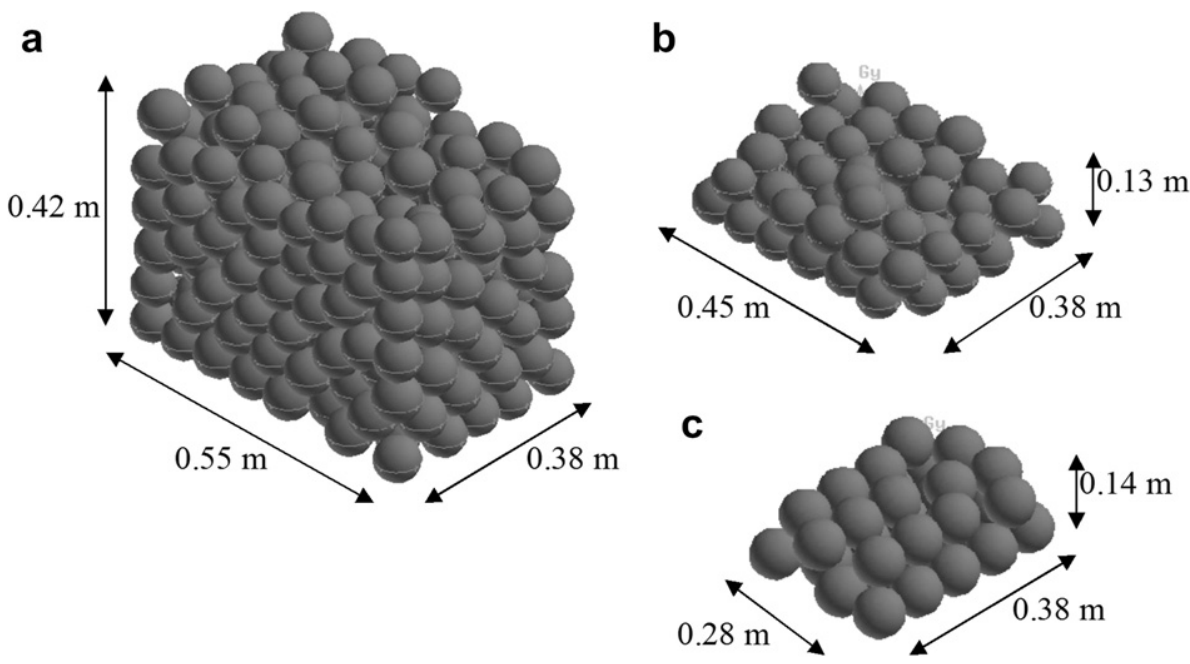

Fig. 1. Stacks of spheres generated using the DE method: $(\mathrm{a})$ case 1 (diameter $=65-75 \mathrm{~mm})$; $(\mathrm{b})$ case $2($ diameter $=65-75 \mathrm{~mm}) ;(\mathrm{c})$ case $3($ diameter $=75 \mathrm{~mm})$.

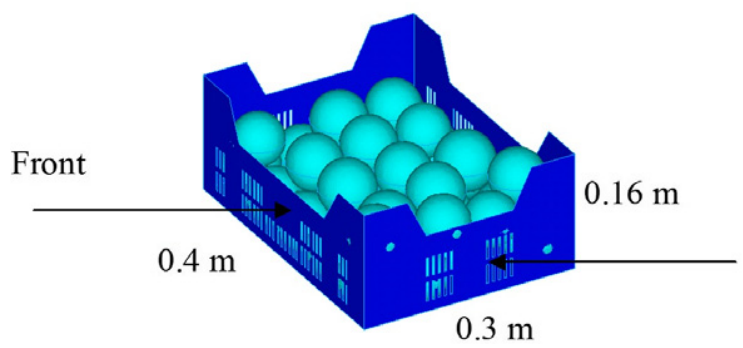

Fig. 2. Vented EPS box loaded with 32 spheres of $75 \mathrm{~mm}$ diameter.

the gap width between box walls was $2 \mathrm{~cm}$; for boxes that were placed one above the other there was a head space of approximately $4.5 \mathrm{~cm}$.

\subsection{CFD model formulation}

\subsubsection{Governing equations}

In Cartesian coordinates, for steady-state incompressible flow and in the absence of external forces, the Reynolds-averaged fluid flow equations are as follows:

$\frac{\partial u_{i}}{\partial x_{i}}=0$

$\rho u_{j} \frac{\partial u_{i}}{\partial x_{j}}=-\frac{\partial p}{\partial x_{i}}+\frac{\partial}{\partial x_{j}} \mu\left(\frac{\partial u_{i}}{\partial x_{j}}+\frac{\partial u_{j}}{\partial x_{i}}\right)+\rho \frac{\partial\left(-\overline{u_{i}^{\prime} u_{j}^{\prime}}\right)}{\partial x_{j}}$

The last term in Eq. (4) can be approximated by

$-\overline{u_{i}^{\prime} u_{j}^{\prime}}=\frac{\mu_{t}}{\rho}\left(\frac{\partial u_{i}}{\partial x_{j}}+\frac{\partial u_{j}}{\partial x_{i}}\right)-\frac{2}{3} k \delta_{i j}$

For the closure of these equations, turbulence models are used. In this study, after comparing the convergence and the accuracy of the solution from different turbulence models (standard $k-\varepsilon$, standard $k-\omega$ and SST), the shear stress transport (SST) model that uses $k-\omega$ in the wall region and $k-\varepsilon$ in the bulk flow region was used (Menter, 1993).

\subsubsection{Geometry and boundary conditions}

The appropriate size of the bulk was enclosed in a rectangular domain. The domain and the bulk had a similar height and width. After analyzing the convergence of the solution and the develop- ment of the flow approaching the bulk and exiting from the domain, distances of $1 \mathrm{~m}$ between the inlet and the bulk and $1.6 \mathrm{~m}$ between the bulk and the outlet were found to be sufficient. The bulks were prepared to give different confinement ratios. From the stack of case 1, two geometries were considered. First, only half of the width of the stack was taken and the top, bottom and side boundaries were no-slip walls; the side on the cut plan was taken as symmetry. Second, a part was cut out from the centre of the stack ( $0.38 \mathrm{~m}$ length, $0.275 \mathrm{~m}$ width and $0.21 \mathrm{~m}$ height) and all the boundaries that enclose the bulk were taken as symmetry. This was assumed to represent the flow through unconfined stack. For the stacks of case 2 and case 3, the first approach was applied. Simulation was also done using the whole stack; all the boundaries that enclose the bulk were taken as no-slip boundary walls. The pressure drop was not significantly different (at 95\% confidence level) from the result obtained from the simulation using the half stack with a symmetry boundary on the cut plane. However, by cutting the stack into half the computational time was decreased by $42.4 \%$.

In the case of vented boxes, the simulation was done for a vented box without any product, for a single box with products and for two boxes in series with a product. The flow was analysed from side, front and bottom directions. At the inlet, uniform airflow with a velocity of $0.01-2.5 \mathrm{~m} / \mathrm{s}$ and $10 \%$ turbulence intensity was applied. The pressure at the outlet was set at atmospheric pressure. A typical horizontal plane with the boundaries is given in Fig. 3.

\subsubsection{Solution procedures}

The CFD code used for this work was Fluent 6.3.26 (Fluent Inc., Lebanon, USA). The governing equations were discretized and numerically solved using the finite volume method. The computational domain was discretized using a tetrahedral hybrid mesh. After comparing the calculated results and the CPU time of the calculation for different mesh sizes, meshes with sizes of $0.005 \mathrm{~m}$ and $0.001 \mathrm{~m}$ for sphere and slot surfaces, respectively and $0.01 \mathrm{~m}$ for the volume were selected (Fig. 3). There was no significant difference (at 95\% confidence level) in the solution when meshes finer than these sizes were used. The total number of cells was in the range of $450,000-1,200,000$, depending on the complexity of the geometry. All the equations were discretized using second order upwind scheme. The pressure-velocity coupling was done using a SIMPLE algorithm. The solution converged to a normalized root mean square residual below $10^{-4}$ of all equations. The calculation 


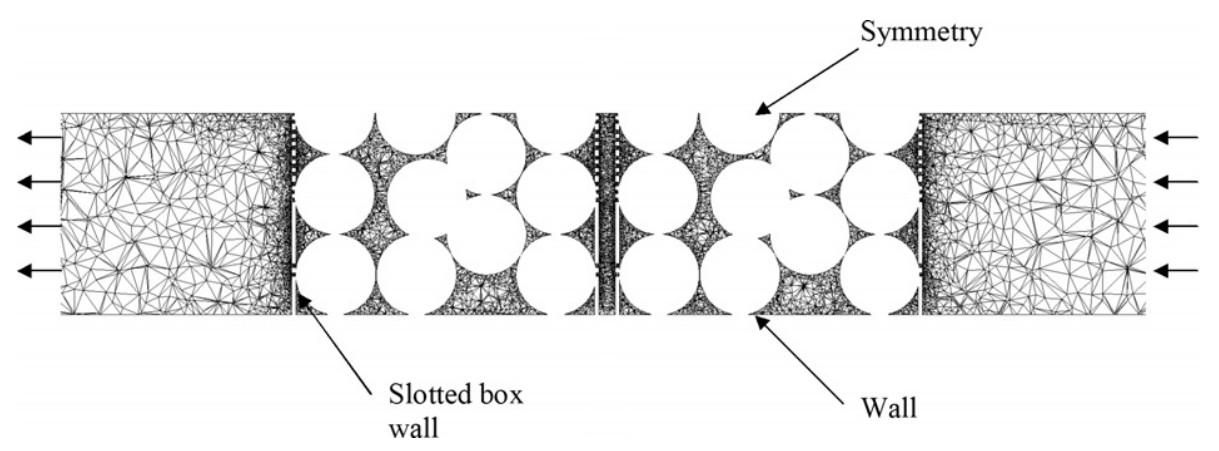

Fig. 3. A typical horizontal plane showing the boundaries, flow direction and computational meshes of two adjacent slotted boxes filled with spherical products (diameter $=75 \mathrm{~mm}$ ).

was done using a Pentium IV, $3.21 \mathrm{GHz}$ WinXp workstation with 3.62 GB Ram. The simulation was steady-state with a total CPU time of calculation in the range of 9-20 h.

\subsection{Validation method}

Measurement of air flow in EPS boxes loaded with 32 spheres of $75 \mathrm{~mm}$ diameter was performed in a small wind tunnel (Hoang et al., 2003). The boxes were randomly filled. Velocity profiles were measured by means of a hot-film omni-directional air velocity transducer (TSI 8475, TSI Incorporated, Shoreview, MN, USA). The operating range of the sensor is $0.05-2.5 \mathrm{~m} / \mathrm{s}$. The factory calibrated accuracy of the sensor is $3 \%$ of the reading or $1 \%$ of the full range. The upstream velocity was adjusted to 0.06 and $0.15 \mathrm{~m} / \mathrm{s}$ in two experimental runs. The vertical air velocity profile in between the spherical particles was measured at 54 positions throughout the box. 3 different vertical planes perpendicular to the air flow, respectively at $1,18.5$ and $30.5 \mathrm{~cm}$ from the inlet side of the box were chosen. There were 18 measurement positions per plane. To prevent the velocity probe from touching the spheres a metal cylindrical frame was used (Fig. 4). At each point where the cylinder frame was placed, measurements were taken at 6 points in the vertical direction.

The validation of the predicted pressure drop was based on previously developed experimental correlations and porous media approaches. For calculating the constants for Darcy-Forchheimer and Ramsin equations for bulk, confined and vented box flows, the equations developed by Ergun (1952), Reichelt (1972) and Smale (2004) were used, respectively.

\section{Results}

\subsection{Bulk and confined flows}

For the different cases, the calculated bulk porosity and confinement constants are given in Table 2 . In the case of nonuniform sized spheres, the mean diameter derived from the distribution of the sphere diameter was taken. A typical simulation result with velocity and pressure contours is given in Fig. 5. The plots show the inhomogeneous flow distribution between the spheres. The velocity in the stack was much higher than the approaching velocity; however, there was also a point of stagnation noticed near the contact point where the velocity was minimal. Near the surface of the confining walls, regions with channel like flow were observed (Fig. 6).

For the different cases mentioned in Sections 2.1 and 2.2.2, the simulated pressure drop was compared with the calculated result from the Darcy-Forchheimer equation. The constants were calculated based on Ergun theory. Confining the bulk product in a wall resulted in a smaller pressure drop than the value obtained from the Ergun equation (Fig. 7). The difference between the simulated and the pressure drop from Ergun equation increased with a decrease in confinement ratio. However, considering a small sample out of a large bulk and setting all the boundaries that enclose the bulk as symmetry produced an average pressure drop that was only $7.8 \%$ higher than the pressure drop from the Ergun equation. Though this agreement is very good, it can be further improved by taking larger bulk sample sizes to minimize edge, entrance and exit effects on the total pressure drop. This shows that using this proce-
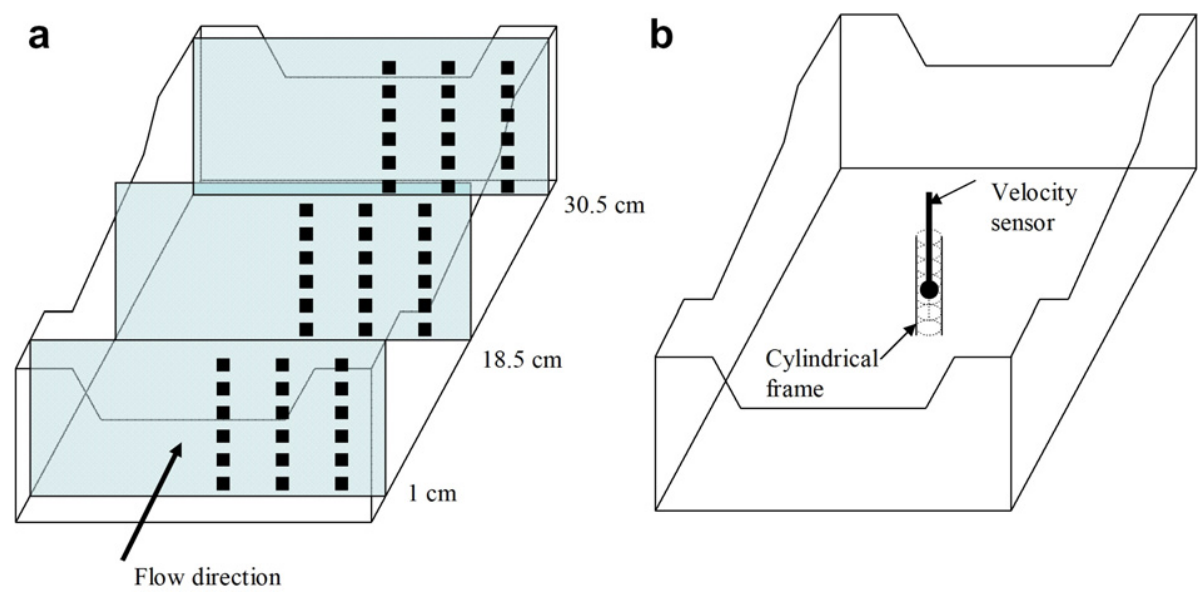

Fig. 4. Experimental set up for velocity measurement inside loaded EPS box: (a) measurement points; (b) metal cylindrical frame that prevent the velocity probe from touching the spheres. 
Table 2

Porosity, confinement ratio and parameters of the equation of Reichelt (1972) for flow inside confined bulks of spheres

\begin{tabular}{lllllll}
\hline & $d_{\mathrm{p}}(\mathrm{m})$ & $D_{\mathrm{h}} / d_{\mathrm{p}}$ & $\varepsilon$ & $K_{1}$ & $A_{\mathrm{w}}$ & $B_{\mathrm{w}}$ \\
\hline${\text { Case } 1^{\mathrm{a}}}^{\mathrm{b}}$ & 0.0702 & 6.780 & 0.4181 & 200.52 & 1.169 & 0.751 \\
${\text { Case } 1^{\mathrm{b}}}^{\mathrm{c}}$ & 0.0702 & $\infty$ & 0.3466 & 187.66 & 1 & 0.535 \\
Case $^{\mathrm{c}}$ & 0.0702 & 2.787 & 0.4380 & 141.39 & 1.428 & 0.984 \\
Case 3 $^{\mathrm{d}}$ & 0.075 & 2.429 & 0.4686 & 132.04 & 1.516 & 1.090 \\
\hline
\end{tabular}

${ }^{a}$ Half of 6 layers of 300 spheres.

b A part cut out from the centre of 6 layers of 300 spheres.

c Two layers of 70 spheres.

d Two layers of 32 spheres.

dure the pressure drop in a bulk with an infinite size could be predicted with a reasonable accuracy.

\subsection{Vented box flow}

The simulation results with velocity and pressure contours for a particular filling are given in Fig. 8. The pressure drop through the vented wall was much higher than the pressure drop through the bulk. According to Smale (2004), the loss at entrance and exit vents contributed $60 \%$ of the total pressure loss. The vertical profile of the average maximum measured and simulated velocity between the spheres was plotted as a function of the distance from the entrance of the box (Fig. 9). The maximum velocity was observed in the head space. The shape of the vertical velocity profile was not affected by the air flow rate. There was a decay of air velocity between the spheres with distance from the box inlet. The simulated velocity was taken from the stacking pattern that gave better agreement with the measured result.

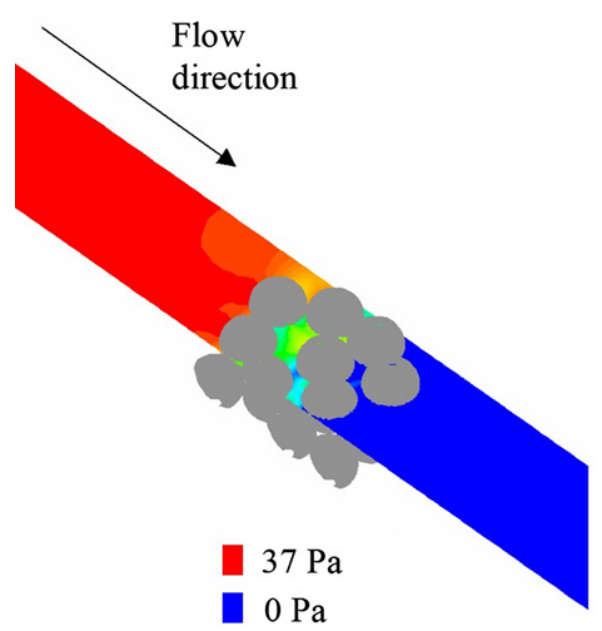

Fig. 10 shows the pressure drop over the individual components of the boxes, the sum of those and the pressure drop over the system as a whole. Summing the individual contributions results in a severe underestimation of the actual total pressure drop. This is true for individual as well as multiple boxes. The total pressure drop was also expressed in the form of Darcy-Forchheimer $\left(\Delta p=-\frac{\mu}{K_{c}} \boldsymbol{u}-\right.$ $\left.\rho \beta_{c} \mathrm{O}^{-d} \boldsymbol{u}^{2}\right)$ and Ramsin power-law equations $\left(\Delta p=-m_{\mathrm{r}} \mathrm{O}^{-d} \boldsymbol{u}^{b}\right)$. For

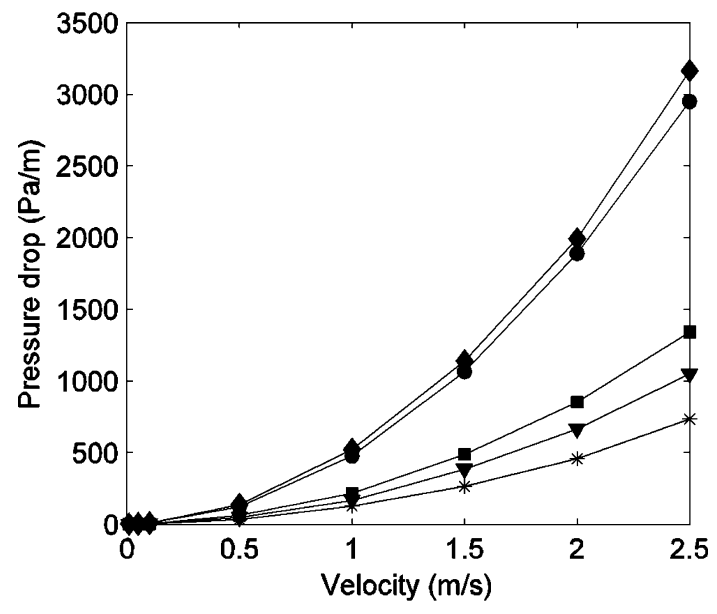

Fig. 7. Pressure drop through bulks of spheres, CFD simulations compared to the equation of Ergun (1952). Simulations were performed on different unconfined and confined stacks: unconfined, a part cut out from the centre of 6 layers of $300 \mathrm{sp}$ heres, $--($ CFD); confined, half of 6 layers of 300 spheres, $-\mathbf{\square}-($ CFD); confined, two layers of 70 spheres, $-\boldsymbol{\nabla}-$ (CFD); confined, two layers of 32 spheres, -*(CFD); - - (Ergun).

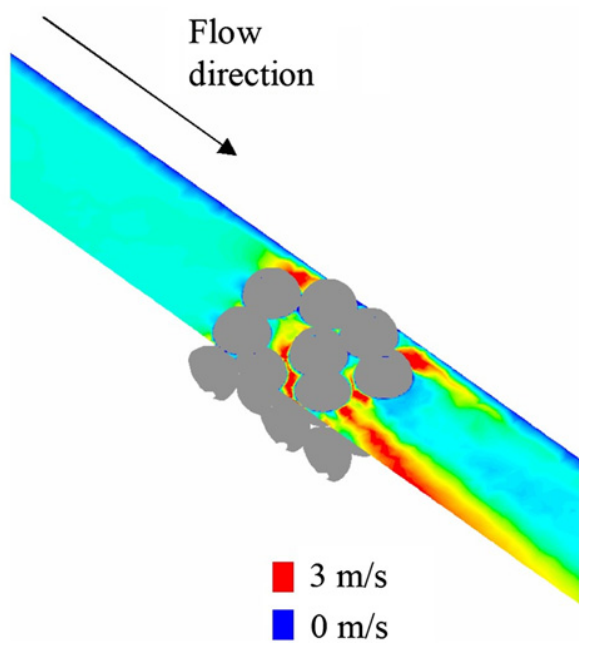

Fig. 5. Simulated pressure (left) and velocity (right) contours of the air flow through a confined bulk of $32 \mathrm{spheres}$ of $75 \mathrm{~mm}$ diameter, superficial velocity $=1 \mathrm{~m} / \mathrm{s}$.

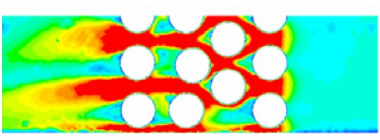

a
Flow direction

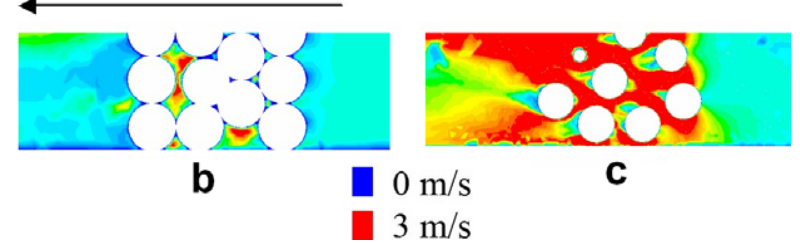

Fig. 6. Simulated velocity contours of the air flow through a confined bulk of 32 spheres of $75 \mathrm{~mm}$ diameter on different horizontal cross sections, superficial velocity $=1 \mathrm{~m} / \mathrm{s}$ : (a) $1 \mathrm{~cm}$ above the bottom wall; (b) $4 \mathrm{~cm}$ above the bottom wall; (c) $1 \mathrm{~cm}$ below the top wall. 

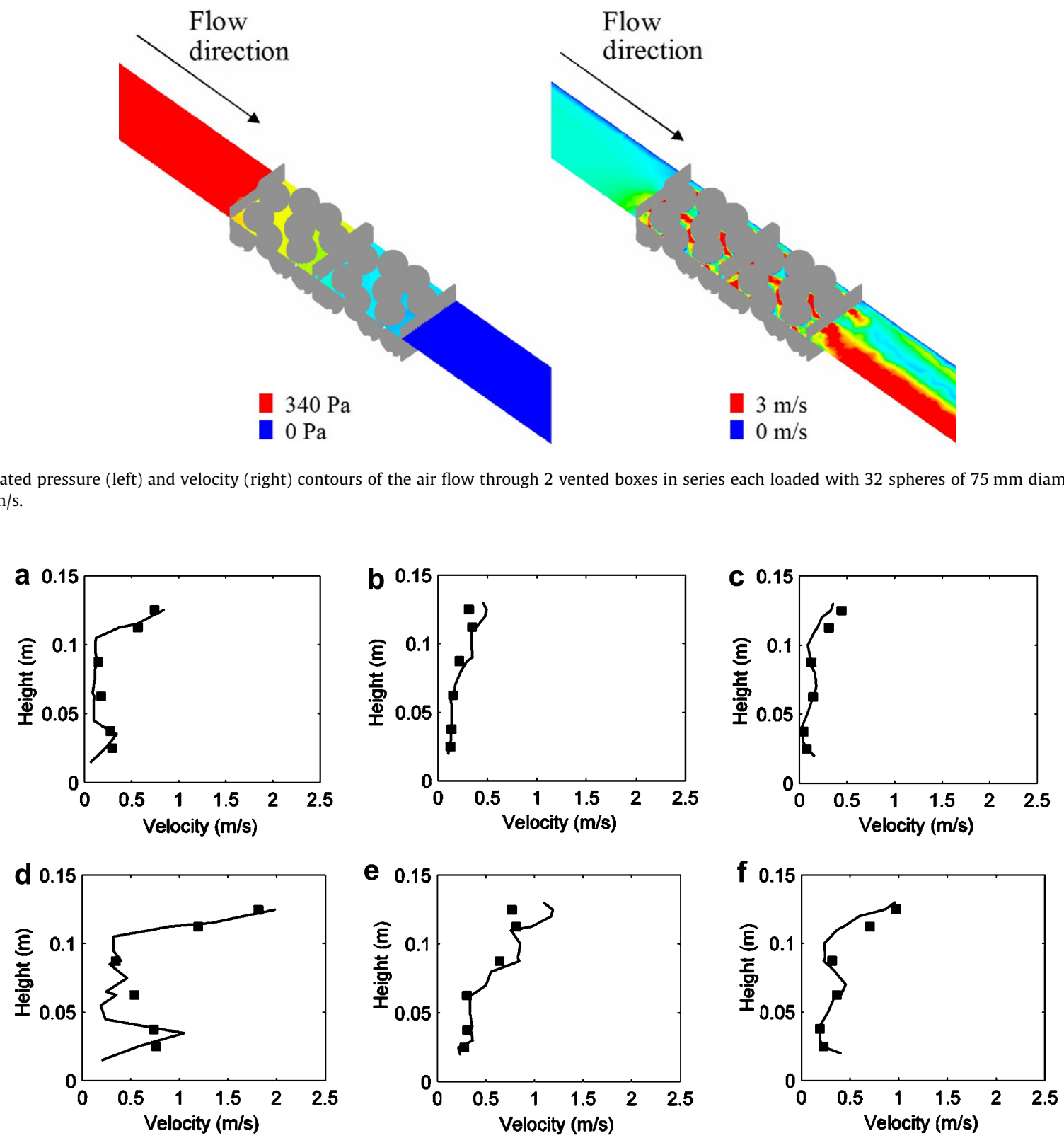

Fig. 9. Measured and simulated vertical profile of the average maximum air velocity between spheres in the EPS box with 32 spheres of 75 mm diameter. Comparison is given for different values of the superficial velocity and at different distances from the entrance of the box: - (CFD), $\mathbf{a}$ (measured); (a) inlet velocity of $0.06 \mathrm{~m} / \mathrm{s}, 1 \mathrm{~cm}$ from entrance; (b) inlet velocity of $0.06 \mathrm{~m} / \mathrm{s}, 18.5 \mathrm{~cm}$ from entrance; (c) inlet velocity of $0.06 \mathrm{~m} / \mathrm{s}, 30.5 \mathrm{~cm}$ from entrance; (d) inlet velocity of $0.15 \mathrm{~m} / \mathrm{s}, 1 \mathrm{~cm}$ from entrance; (e) inlet velocity of $0.15 \mathrm{~m} / \mathrm{s}, 18.5 \mathrm{~cm}$ from entrance; (f) inlet velocity of $0.15 \mathrm{~m} / \mathrm{s}, 30.5 \mathrm{~cm}$ from entrance.

$O=100 \%$, the equations represent the flow through the bulk alone. The parameters $\frac{1}{K_{\mathrm{c}}}, \beta_{\mathrm{c}}$ and $m_{\mathrm{r}}$ were determined from the corresponding relations that were developed for a flow over the bulk alone. Fig. 11 compares the simulated and calculated (based on the above fitted equations) total pressure drop. The pressure drop decreases with an increase in vent hole ratio and both models fit the results well. The average relative differences between the pressure drops that were obtained from the simulation and those calculated from fitted Darcy-Forchheimer and Ramsin equations were $9.44 \%$ and $10.13 \%$, respectively. The relative difference $(E)$ was calculated using the following relation:

$E=\frac{1}{N} \sum \frac{\left|p_{\mathrm{s}}-p_{\mathrm{c}}\right|}{p_{\mathrm{s}}} \times 100$

For the different cases, the values of $\frac{1}{K_{\mathrm{c}}}, \beta_{\mathrm{c}}, d, b, m_{\mathrm{r}}$ and $E$ are given in Table 3.

\section{Discussion}

The simulated results from the confined bulks were compared with the calculated results from the equation proposed by Reichelt (1972). By fitting a large experimental dataset, the values of the constants $K_{1}, k_{1}$ and $k_{2}$ for spherical particles were found to be approximately equal to $154,1.15$ and 0.87 , respectively (Eisfeld and Schnitzlein, 2001). On the average, the simulated pressure drop was $14.9 \%$ higher than the pressure drop that was calculated based on the above constants (Fig. 12). Generally, there was a reasonable agreement with an over prediction by the CFD model. When the simulated results were fitted to the form recommended by Reichelt (1972), the values of constants $K_{1}, k_{1}$ and $k_{2}$ were equal to $165.4,1.194$ and $0.839\left(r^{2}=0.983\right)$, respectively.

The simulated results were also fitted to the Ramsin equation, the values of $a$ and $b$ for the different cases are given in Table 4 


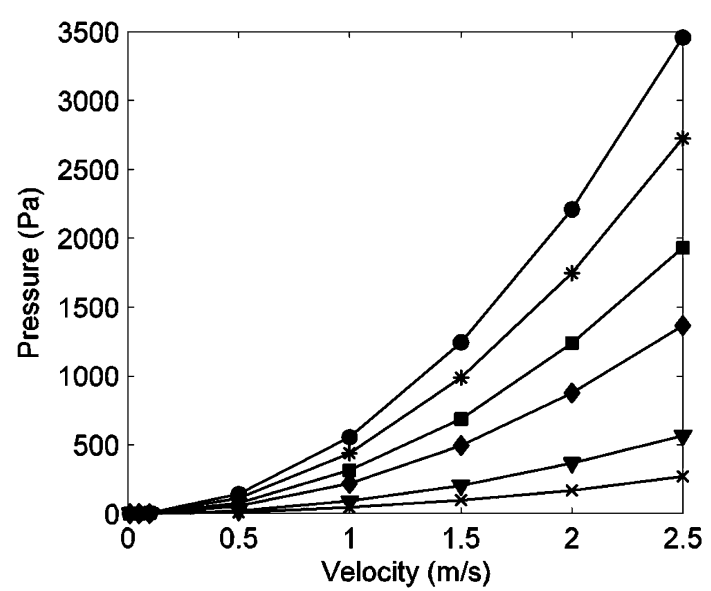

Fig. 10. Pressure drop through vented EPS boxes loaded with 32 spheres of $75 \mathrm{~mm}$ diameter per box: bulk without box, $-\times-$; box without bulk, $-\mathbf{\nabla}-; 1$ loaded box from sum of pressure drops $(2(-\nabla-)+-\times-),--; 1$ loaded box from CFD simulation, $-\mathbf{\square}-; 2$ loaded boxes from sum of pressure drops $(4(-\boldsymbol{\nabla}-)+2(-\times-))$, $-*-$; 2 loaded box from CFD simulation, $-\bullet-$.

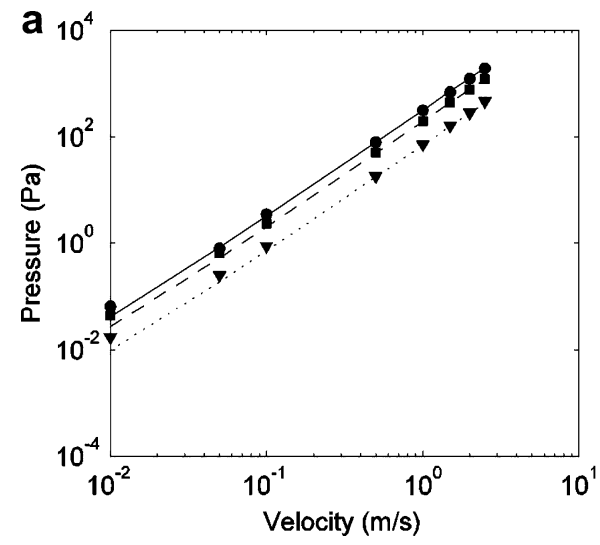

$\left(r^{2} \geqslant 0.997\right)$. The coefficient $a$ and the exponent $b$ were decreasing with confinement ratio. The fit of the result from Darcy-Forchheimer equation was better than the Ramsin equation. The average relative differences between the simulated pressure drop and those calculated from fitted Darcy-Forchheimer and Ramsin equations were $7.25 \%$ and $12.21 \%$, respectively. In both cases this difference was higher for low inlet velocity $(<0.1 \mathrm{~m} / \mathrm{s})$. This shows limitation of both the Darcy-Forchheimer and Ramsin equations for describing the pressure drop for low Reynolds number flow. Since the EPS box considered in the simulation is the smallest possible for the handling of such horticultural products (product with an effective diameter less than $75 \mathrm{~mm}$ ), it is less likely to get a confinement ratio less than 2.429; as a result, it is reasonable to approximate the value of the exponent $b$ in the range of 1.761.81. Taking the average value of $b\left(\frac{p}{T}=a \mathbf{u}^{1.7871}\right)$ gave an average relative error of $12.95 \%$.

Four different random stacking in EPS boxes were analysed (Fig. 13). However, different stacking pattern gave different velocity profile inside the bulk. The overall average relative errors with the measured velocity profile were $56.72 \%, 35.10 \%, 21.3 \%$ and $28.64 \%$ for stacking pattern I, II, III and IV, respectively. Stacking

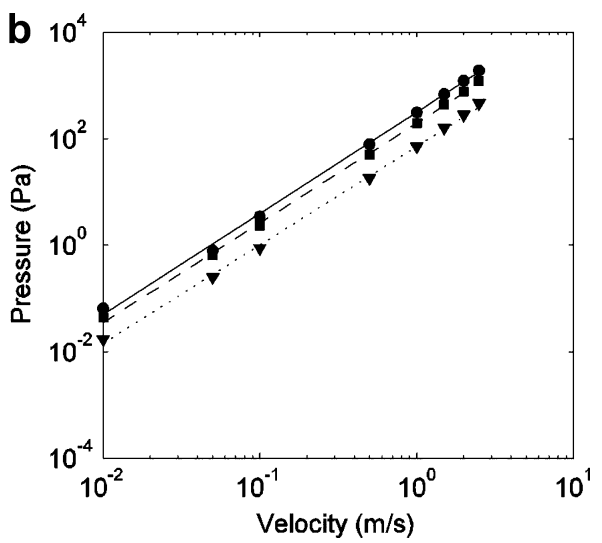

Fig. 11. Pressure drop through vented EPS boxes for different vent hole ratios: (a) fitted with the Darcy-Forchheimer equation; (b) fitted with the Ramsin equation; $O=11.03 \%, \bullet$ (CFD), - (fitted); $O=14.36 \%, \square$ (CFD), - - - (fitted); $O=19.11 \%, \boldsymbol{\nabla}$ (CFD), $\cdots$ (fitted).

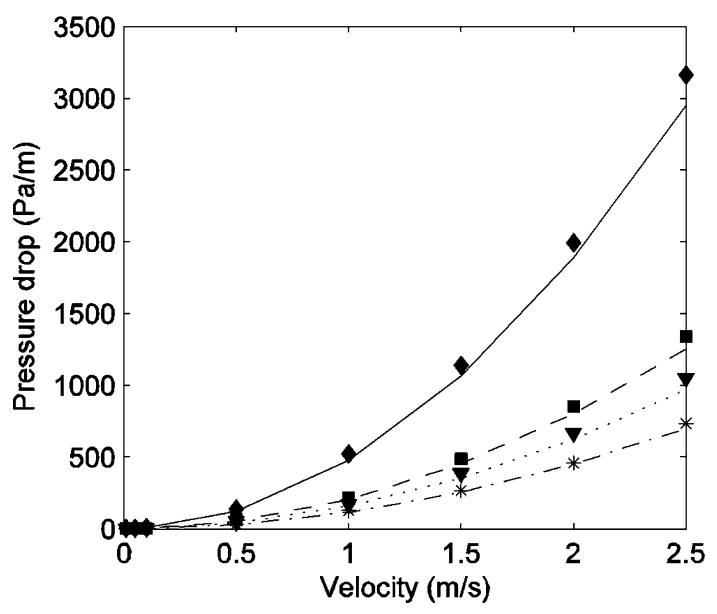

Fig. 12. Pressure drop through bulks of spheres, CFD simulations compared to the equation of Reichelt (1972), based on constants from Eisfeld and Schnitzlein (2001). Simulations were performed on different unconfined and confined stacks: unconfined, cut out from the centre of 6 layers of 300 spheres, $\downarrow$ (CFD), - (Reichelt); confined, half of 6 layers of 300 spheres, $\mathbf{a}$ (CFD), - - - (Reichelt); confined, two layers of 70 spheres, $\mathbf{\nabla}$ (CFD), (Reichelt); confined, two layers of 32 spheres, * (CFD), - - (Reichelt).
Table 3

Parameters of Darcy-Forchheimer and Ramsin equations for flow inside loaded vented boxes

\begin{tabular}{|c|c|c|c|c|c|c|c|c|}
\hline \multicolumn{5}{|c|}{ Darcy-Forchheimer equation } & \multicolumn{4}{|c|}{ Ramsin equation } \\
\hline 0 & $\frac{1}{K_{\mathrm{c}}}$ & $\beta_{\mathrm{c}}$ & $d$ & E & $m_{\mathrm{r}}$ & $d$ & $b$ & $E$ \\
\hline \multicolumn{9}{|c|}{ One box } \\
\hline 11.03 & 54816.7 & 35.46 & 0.9064 & 6.65 & 45.78 & 0.8746 & 1.9005 & 11.32 \\
\hline 14.36 & 43244.4 & 28.53 & 0.8935 & 9.53 & 37.32 & 0.8512 & 1.8721 & 8.29 \\
\hline 19.10 & 15894.4 & 12.94 & 0.8999 & 12.81 & 17.28 & 0.8537 & 1.8483 & 10.55 \\
\hline \multicolumn{9}{|c|}{ Two boxes } \\
\hline 11.03 & 109633.4 & 70.92 & 0.8493 & 6.74 & 91.56 & 0.8177 & 1.8887 & 11.28 \\
\hline 14.36 & 86488.8 & 57.06 & 0.8122 & 10.94 & 74.64 & 0.7703 & 1.8471 & 10.05 \\
\hline 19.10 & 31788.8 & 25.88 & 0.9601 & 9.96 & 34.56 & 0.8979 & 1.8623 & 9.50 \\
\hline
\end{tabular}

Table 4

Confinement ratio and parameters of Ramsin equation for flow inside confined bulks

\begin{tabular}{lllll}
\hline & $d_{\mathrm{p}}(\mathrm{m})$ & $D_{\mathrm{h}} / d_{\mathrm{p}}$ & $a$ & $b$ \\
\hline${\text { Case } 1^{\mathrm{a}}}_{\text {Case }^{\mathrm{b}}}^{\mathrm{b}}$ & 0.0702 & 6.780 & 226.78 & 1.7970 \\
Case 2 $^{\mathrm{c}}$ & 0.0702 & $\infty$ & 530.64 & 1.8106 \\
Case 3 $^{\mathrm{d}}$ & 0.0702 & 2.787 & 178.16 & 1.7815 \\
\hline
\end{tabular}

${ }^{\text {a }}$ Half of 6 layers of 300 spheres.

b A part cut out from the centre of 6 layers of 300 spheres.

c Two layers of 70 spheres.

d two layers of 32 spheres. 


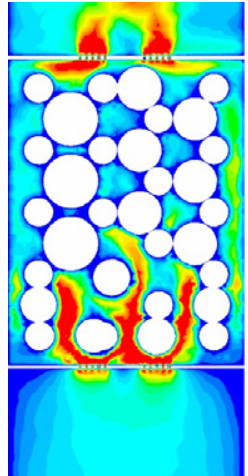

a

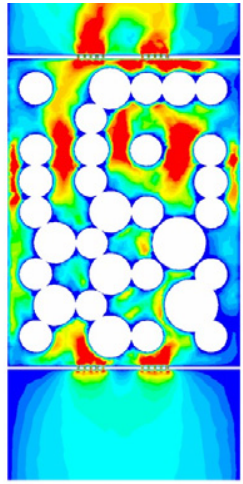

b

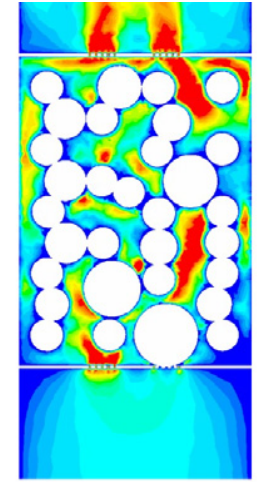

C

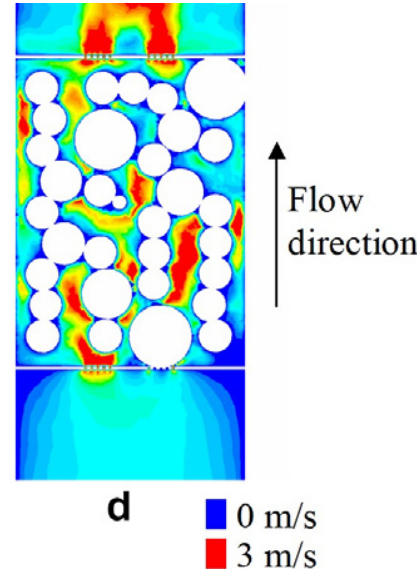

Fig. 13. Simulated velocity contours inside a single EPS box loaded with 32 randomly packed spheres of 75 mm diameter, horizontal cross section at $7 \mathrm{~cm}$ above the bottom of the box, superficial velocity = $1 \mathrm{~m} / \mathrm{s}$ : (a) stacking pattern I; (b) stacking pattern II; (c) stacking pattern III; (d) stacking pattern IV.

pattern III did represent the experimental stacking pattern better than the others. On the other hand, we did not find significant differences in pressure drop for the different random configurations. In such random arrangement the pressure drop is proportional to the tortuosity of the flow (Wang et al., 1999). This shows that the tortuosity of different random configuration generated were almost the same. Therefore, it seems not necessary to take into account the stacking variability to assess pressure drop-flow rate relationships in randomly filled vented boxes. However, this does not mean that the pressure drop through straight, staggered, square staggered or other stacking patterns is similar to the random pattern. Due to the difference in tortuosity, the pressure drop through these stacking patterns is different. Chau et al. (1985) observed a difference in pressure drop through the different stacking patterns, the highest and the lowest was for the staggered and straight arrangements, respectively.

The pressure drop in vented box with product was higher than the sum of the pressure drops across each side of the box and the product. This is similar to the experimental result that was reported by Chau et al. (1985) and is due to the obstruction of part of the vented holes with the product surface resulting in higher entrance losses. For flow through a vented box with products, a linear addition of the pressure by considering as series of resistances seriously underestimates the real pressure drop. In addition, the pressure drop through two boxes that were placed side by side was on the average $11.90 \%$ lower than the sum of individual pressure drop. When the two boxes were placed one above the other, the pressure drop was $5.8 \%$ higher than the sum of the individual pressure drop. Smale (2004) did propose an additive method, and the difference was not that large as found here. The present results do raise questions on the applicability of such method. A further study that takes into account the gap width and the vent design in both side of the gap (for instance, the top of the EPS box is open) could help to develop a better correlation method.

The fitted pressure drop equations incorporate a term that takes into account the effect of vent hole ratio. None of the values of the exponent $d$ found here were close to 1.5 as reported by van der Sman (2002). A similar finding was also reported from the measured results of Smale (2004). Taking the average values of $b$ and $d\left(\Delta p=-\frac{\mu}{K_{\mathrm{c}}} \boldsymbol{u}-\rho \beta_{\mathrm{c}} O^{-0.8869} \boldsymbol{u}^{2}\right.$, Darcy-Forchheimer equation; $\Delta p=$ $-m_{\mathrm{r}} \mathrm{O}^{-0.8442} \boldsymbol{u}^{1.8698}$, Ramsin equation) gave an average relative error of $13.16 \%$ and $12.10 \%$ for Darcy-Forchheimer and Ramsin, respectively. The values of the loss coefficients $\frac{1}{K_{\mathrm{c}}}, \beta_{\mathrm{c}}$ and $m_{\mathrm{r}}$ in the three directions were different $(O=11.03 \%$, side; $O=14.36 \%$, front; $O=19.11 \%$, bottom). This shows that for predicting flow inside boxes with horticultural products the assump- tion of isotropic loss coefficients is not correct. Based on these previously unknown results, developing a general rule to explain the trends of $b$ and $d$ for any types of box designs may not be reasonable. However, the presented DE-CFD methodology could be used to analyse a large number of cases and develop more generic correlations for box configurations.

\section{Conclusions}

A combined discrete element (DE) and computational fluid dynamics (CFD) model allows analyzing explicitly the airflow through the air gaps in the box and in the voids between the stacked products. The approach was validated by different methods and compared well to different practical cases. The flow resistance was affected by the confinement ratio, product size, porosity, box vent hole ratio, and much less by the random filling. The air flow inside the stack was very heterogeneous. The flow resistance of the flow through the bulk and vented boxes can be expressed either in the form of Darcy-Forchheimer or Ramsin equations with a reasonable accuracy. For flow through a vented box with products, a linear addition of the individual pressure drops of the flow through the box and the bulk by considering as series of resistances seriously underestimates the real pressure drop.

The novelty of the developed methodology is its use for investigating the detailed 3-D flow characteristics down to the level of individual pores that cannot be explained by porous media approaches. On the other hand, the presented approach is suitable for in silico experiments to obtain new and more accurate pressure drop correlations to predict large scale cooling of boxes with horticultural products.

\section{Acknowledgement}

K.U. Leuven (Project OT 04/31, the Interfaculty Council for Development Co-operation (IRO) and the Industrial Research Fund) is gratefully acknowledged for financial support.

\section{References}

Alvarez, G., Flick, D., 1999a. Analysis of heterogeneous cooling of agricultura products inside bines. Part I: Aerodynamic study. Journal of Food Engineering 39, 227-237.

Alvarez, G., Flick, D., 1999b. Analysis of heterogeneous cooling of agricultural products inside bines. Part II: Thermal study. Journal of Food Engineering 39, 239-245.

Alvarez, G., Flick, D., 2007. Modelling turbulent flow and heat transfer using macroporous media approach used to predict cooling kinetics of stacks of food products. Journal of Food Engineering 80, 391-401. 
Beetstra, R., van der Hoef, M.A., Kuipers, J.A.M., 2006. A Lattice-Boltzmann simulation study of the drag coefficient of clusters of spheres. Computers \& Fluids 35, 966-970.

Beetstra, R., van der Hoef, M.A., Kuipers, J.A.M., 2007. Drag force of intermediate reynolds number flow past mono- and bidisperse array of spheres. AICHE Journal 53 (2), 489-501.

Chau, K.V., Gaffney, J.J., Baird, C.D., Church, G.A., 1985. Resistance to airflow of oranges in bulk and in cartons. Transactions of the ASAE 28 (6), 2083-2088.

Deen, N.G., Van Sint Annaland, M., Kuipers, J.A.M., 2006. Detailed computational and experimental fluid dynamics of fluidized beds. Applied Mathematical Modelling 30, 1459-1471.

Deen, N.G., Van Sint Annaland, M., Van der Hoef, M.A., Kuipers, J.A.M., 2007. Review of discrete particle modeling of fluidized beds. Chemical Engineering Science $62,28-44$.

Di Felice, R., Gibilaro, L.G., 2004. Wall effects for the pressure drop in fixed beds. Chemical Engineering Science 59, 3037-3040.

Dixon, A.G., Nijemeisland, M., 2001. CFD as a design tool for fixed-bed reactors. Industrial and Engineering Chemistry Research 40, 5246-5254.

Dixon, A.G., Nijemeisland, M., Stitt, E.H., 2005. CFD study of heat transfer near and at the wall of fixed reactor tube: effect of wall conduction. Industrial and Engineering Chemistry Research 44, 6342-6353.

Eisfeld, B., Schnitzlein, K., 2001. The influence of confining walls on the pressure drop in packed beds. Chemical Engineering Science 56, 4321-4329.

Ergun, S., 1952. Fluid flow through packed columns. Chemical Engineering Progress $48,89-94$.

Forchheimer, P., 1901. Wasserbewegung durch Boden. Zeitschrift des Vereines Deuts Ingenieure 45, 1736-1741.

Freund, H., Zeiser, T., Huber, F., Klemm, E., Brenner, G., Durst, F., Emig, G., 2003. Numerical simulation of single phase reacting flows in randomly packed fixedbed reactors and experimental validation. Chemical Engineering Science 58, 903-910.

Hill, R.J., Koch, D., Ladd, A.J.C., 2001. Moderate-Reynolds-number flows in ordered and random arrays of spheres. Journal of Fluid Mechanics 448, 243-278.

Hoang, M.L., Verboven, P., Baelmans, M., Nocolaï, B.M., 2003. A continuum model for airflow, heat and mass transfer in bulk of chicory roots. Transactions of the ASAE 46 (6), 1603-1611.
Li, J., Kuipers, J.A.M., 2007. Effect of competition between particle-particle and gasparticle interactions on flow pattern in dense gas-fluidized beds. Chemical Engineering Science 62, 3429-3442.

Menter, F.R., 1993. Zonal two equation $k-\varepsilon$ turbulence models for aerodynamic flows. Paper No. 93-2906. American Institute of Aeronautics and Astronautics, 24th Fluid Dynamics Conference, Orlando, USA.

Nijemeisland, M., Dixon, A.G., 2004. CFD study of fluid flow and wall heat transfer in a fixed bed of spheres. AICHE Journal 50, 906-921.

Reichelt, W., 1972. Zur Berechnung des Druckverlustes einphasig durchströmter Kugel-und Zylinderschüttungen. Chemie-Ingenieur-Technik 44, 10681071.

Smale, N.J., 2004. Mathematical modelling of airflow in shipping systems: model development and testing. Ph.D. thesis, Massey University, Palmerston North, New Zealand.

Tijskens, E., Ramon, H., De Baerdemaeker, J., 2003. Discrete element modelling for process simulation in agriculture. Journal of Sound and Vibration 266, 493514.

van der Hoef, M.A., van Sint Annaland, M., Kuipers, J.A.M., 2004. Computational fluid dynamics for dense gas-solid fluidized beds: a multi-scale modeling strategy. Chemical Engineering Science 59, 5157-5165.

van der Sman, R.G.M., 2002. Prediction of air flow through a vented box by the Darcy-Forchheimer equation. Journal of Food Engineering 55, 49-57.

Verboven, P., Hoang, M.L., Baelmans, M., Nicolaï, B.M., 2004. Airflow through beds of apples and chicory roots. Biosystems Engineering 88 (1), 117-125.

Verboven, P., Flick, D., Nicolaï, B.M., Alvarez, G., 2006. Modelling transport phenomena in refrigerated food bulks, packages and stacks: basics and advances. International Journal of Refrigeration 29, 985-997.

Vingeault, C., Goyette, B., 2002. Design of plastic container opening to optimize forced-air precooling of fruits and vegetables. Applied Engineering in Agriculture 18 (1), 73-76.

Vingeault, C., Markarian, N.R., da Silva, A., Goyette, B., 2004. Pressure drop during forced-air ventilation of various horticultural produce in containers with different opening configurations. Transactions of the ASAE 47 (3), 807814.

Wang, X., Tahauvin, F., Mohanty, K.K., 1999. Non-Darcy flow though anisotropic porous media. Chemical Engineering Science 54, 1859-1869. 